\title{
A Educação Infantil no contexto da pandemia: os possíveis enfrentamentos após a publicação do Parecer 05/2020
}

\author{
A Educação Infantil no contexto da pandemia: os possíveis \\ enfrentamentos após a publicação do Parecer 05/2020
}

\section{La educación infantil en el contexto de la pandemia: los posibles enfrentamientos posteriores a la publicación del Parecer 05/2020}

Cassiana Magalhães 1

https://orcid.org/0000-0002-6609-69IX

Cristiane dos Santos Farias²

https://orcid.org/0000-000 I-6720-5033

\begin{abstract}
Resumo: $O$ presente artigo pretende discutir o Parecer 05/2020 do Conselho Nacional de Educação (CNE) e os possíveis enfrentamentos no contexto da Educação Infantil. A questão orientadora foi delineada da seguinte forma: como a Educação Infantil é afetada pela pandemia da COVID-19? A questão se faz necessária pela garantia dos direitos conquistados duramente no campo da educação das crianças, especialmente ao fato de serem educadas em espaços coletivos, não domésticos (BRASIL, 2009), e agora na possibilidade de realização de atividades a distância, especialmente na modalidade EAD, por meio de videoaulas e outros recursos virtuais para crianças pequenas, o que pode demarcar ainda mais as condições de desigualdade social. A composição da escrita é de cunho bibliográfico e os resultados encaminham para a necessidade de enfrentamento por meio da resistência, o que não significa abandonar as crianças em tempos de pandemia, ao contrário, é necessário criar as formas mais adequadas de atendê-las.
\end{abstract}

Palavras-chave: Pandemia. Parecer 05/2020. Educação Infantil.

Abstract: The current article aims to discuss the Opinion 05/2020 from Conselho Nacional de Educação (CNE) [The National Education Board] and the possible ways of handling it in the context of Childhood Education. This

\footnotetext{
' Pós-doutora em Educação pela Universidade de Évora - Portugal. Doutorado em Educação (UNESP - Marília - SP); Mestrado em Educação (UEL - Londrina - PR). Líder do grupo de pesquisa Travessias Luso-Brasileiro na Educação da Infância. Docente do Departamento de Educação da Universidade Estadual de Londrina cassiana@uel.br

${ }^{2}$ Mestra em Educação pela Universidade Estadual de Londrina - PR. Integrante do grupo de pesquisa Travessias Luso-Brasileiro na Educação da Infância. Docente Auxiliar do Departamento de Educação da Universidade Estadual de Londrina - Docente da Educação Básica na etapa da Educação Infantil da Prefeitura Municipal de Educação de Londrina-PR e tutora presencial de licenciaturas da Universidade do Norte do Paraná crisfarias@uel.br
}

Olhar de professor, Ponta Grossa, v. 24, p. I-9, e-15877.019, 2021.

Disponível em <https://revistas2.uepg.br/index.php/olhardeprofessor> 
study sought to answer the following question: How is Childhood Education affected by COVID-I9 Pandemic? It justifies itself for ensuring the rights hardly conquered in the field of childhood education, especially due to the fact of being educated in collective, non-domestic environments (BRASIL, 2009) and the rising possibility of remote activities, especially on distance learning, by online lessons and other virtual resources for the young children, which could exacerbate even more the social inequality. The writing composition was made by bibliographic sources and the results indicate the need to face this issue through resistance, which doesn't mean to set aside children in these pandemic times, on the contrary, it's necessary to make proper ways to assist them. Keywords: Pandemic. Opinion 05/2020. Childhood Education.

Resumen: El presente artículo pretende discutir el Parecer 05/2020 del Consejo Nacional de Educación (CNE) y los posibles enfrentamientos en el contexto de la Educación Infantil. La cuestión orientadora fue delineada de la siguiente forma: ¿cómo la Educación Infantil es afectada por la pandemia de la COVID-19? La cuestión se hace necesaria por la garantía de los derechos conquistados duramente en el campo de la educación de los niños, especialmente al facto de que sean educadas en espacios colectivos, no domésticos (BRASIL, 2009), y ahora en la posibilidad de realización de actividades a distancia, especialmente en la modalidad EAD, por medio de clases en video y otros recursos virtuales para niños pequeños, o que puede demarcar aún más las condiciones de desigualdad social. La composición de la escrita es de cuño bibliográfico y los resultados encaminan para la necesidad de enfrentamiento por medio de la resistencia, lo que no significa abandonar los niños en tiempos de pandemia, al contrario, es necesario criar las formas más adecuadas en que se las atenda.

Palabras-clave: Pandemia. Parecer 05/2020. Educación Infantil.

\section{Introdução}

Em dezembro de 2019 foi confirmado o primeiro caso da doença COVID-19 no continente asiático. A Organização Mundial da Saúde (OMS) foi alertada sobre vários casos de pneumonia na cidade de Wuhan, província de Hubei, na República Popular da China. Tratava-se de um novo tipo de coronavírus que não havia sido identificado antes em seres humanos.

A Organização Mundial da Saúde (OMS) declarou, em 30 de janeiro de 2020, que o surto da doença causada pelo novo coronavírus (COVID-19) constitui uma Emergência de Saúde Pública de Importância Internacional - o mais alto nível de alerta da Organização, conforme previsto no Regulamento Sanitário Internacional. Em II de março de 2020, a COVID-I9 foi caracterizada pela OMS como uma pandemia. No dia 19 de março de 2020, a OMS declarou a disseminação do vírus e recomendou três ações básicas para contê-la: isolamento e tratamento dos casos identificados, testes massivos e distanciamento social.

No Brasil, pouco antes desse anúncio da OMS, já havia sido declarado estado de Emergência em Saúde Pública de Importância Nacional (fevereiro de 2020). Porém, somente após a declaração de Pandemia é que estados e municípios iniciaram a edição de decretos e instrumentos legais e normativos para o enfrentamento da COVID-19.

Assim como nas diversas esferas da vida, a escola também foi fortemente afetada - a primeira medida foi a suspensão do calendário escolar. Em consonância com a Política educacional de cenário mundial, as medidas tomadas pelo Brasil foram bastante influenciadas pela Organização para a Cooperação e Desenvolvimento Econômico (OCDE). 
Neste contexto, questionamos: como a Educação Infantil é afetada pela pandemia da COVID19? Para tanto, objetivamos discutir o Parecer 05/2020 do Conselho Nacional de Educação (CNE) e os possíveis enfrentamentos no contexto da Educação Infantil. Almejamos com o texto contribuir com o debate no sentido de reflexão, de memória histórica, especialmente na garantia dos direitos das crianças à educação de qualidade e a luta constante pela diminuição das desigualdades sociais.

\section{O Parecer 05/2020 e os possíveis enfrentamentos no contexto da Educação Infantil}

Diante da situação emergente de saúde pública, no dia 18 de março o CNE lança uma Nota de gestão do calendário e a forma de organização, realização ou reposição de atividades acadêmicas e escolares (BRASIL, 2020a). Essa nota deixa a Educação Infantil de fora das ações que permitem a modalidade EAD, prescrita na quinta ação preventiva:

5. no exercício de sua autonomia e responsabilidade na condução dos respectivos projetos pedagógicos e dos sistemas de ensino, compete às autoridades dos sistemas de ensino federal, estaduais, municipais e distrital, em conformidade com o Decreto $\mathrm{n}^{\circ}$ 9.057, de 25 de maio de 2017, autorizar a realização de atividades a distância nos seguintes níveis e modalidades: I - ensino fundamental, nos termos do $\S 4^{\circ}$ do art. 32 da Lei $n^{\circ}$ 9.394, de 20 de dezembro de 1996; II - ensino médio, nos termos do $§$ II do art. 36 da Lei n 9.394, de 1996; III - educação profissional técnica de nível médio; IV - educação de jovens e adultos; e V - educação especial (BRASIL, 2020a, grifo nosso).

Ora, na legislação brasileira não há previsão de EAD para a Educação Infantil. Quanto à flexibilização do calendário, a primeira manifestação presidencial foi a Medida Provisória n 934, em 01 de abril de 2020. Nela, a preocupação foi a "flexibilização" do calendário escolar, a qual se encontra em tramitação para aprovação do Congresso Nacional, atualmente com mais de 200 emendas. Vejamos o trecho que motivou as ações dos sistemas de ensino:

Art. $1^{\circ} \mathrm{O}$ estabelecimento de ensino de educação básica fica dispensado, em caráter excepcional, da obrigatoriedade de observância ao mínimo de dias de efetivo trabalho escolar, nos termos do disposto no inciso I do caput e no $\S$ lo do art. 24 e no inciso II do caput do art. 3I da Lei $n^{\circ} 9.394$, de 20 de dezembro de 1996, desde que cumprida a carga horária mínima anual estabelecida nos referidos dispositivos, observadas as normas a serem editadas pelos respectivos sistemas de ensino (BRASIL, 2020b).

Temos o calendário normatizado pela Lei n 9.394/96 - LDB (BRASIL, 1996), que determina no mínimo 200 dias letivos e 800 horas para a sua realização e que a frequência da criança na Educação Infantil tenha o mínimo de $60 \%$ de carga horária, sendo que não implica em reprovação por parte da criança caso não seja cumprida.

Quando a MP 934/2020 permite o descumprimento dos 200 dias letivos e mantém as 800 horas, a contradição se instala. A medida tomada pelos gestores foi levada a conceber a educação 
remota como saída para o paradoxo e, dessa forma, o calendário foi retomado por muitas instituições, conduzidos pelos seus Sistemas de Ensino e Conselhos Estaduais e Municipais de Educação, com a medida da utilização de atividades remotas para todas as modalidades de ensino, inclusive na Educação Infantil.

Um grande movimento se fez em torno dessa ação, por meio de consulta pública divulgada em edital no dia 17 de abril pelo CNE, a partir das "orientações em nível nacional a respeito da reorganização do calendário escolar e da possibilidade de cômputo de atividades não presenciais para fins de cumprimento da carga horária mínima anual” (BRASIL, 2020c).

Em resposta ao edital, os Fóruns de Educação Infantil, vinculados ao Movimento Interfóruns de Educação Infantil do Brasil (MIEIB), se posicionaram, resultando no documento "Compilados de Contribuições: à Proposta de Parecer que trata da reorganização dos Calendários Escolares e a Atividades Pedagógicas não Presenciais durante o período da pandemia da COVID-19"3. O documento traz em seu bojo a defesa do MIEIB:

41. no "que concerne à educação das crianças de 0 a 5 anos e onze meses, a flexibilização do calendário deve e pode estar, também, acompanhada da flexibilização da carga horária anual. $O$ não cumprimento da frequência, bem como o não cumprimento da carga horária anual dos bebês e crianças pequenas em creches e pré-escolas não trará prejuízos maiores do que os já causados pelo avanço da Covid-19. Em suma, consideramos que a função social atribuída pela LDB 9.394/96 à educação infantil, ratificada pelas normativas deste Conselho, compreende creches e pré-escolas como espaços coletivos não domésticos - o que prevê que as experiências vivenciadas nas instituições de educação infantil são, em grande medida, distintas das vividas no contexto familiar" (CAMPANHA NACIONAL PELO DIREITO À EDUCAÇÃO, 2020, p. 12).

Para total desapontamento desse grande esforço da sociedade que se mobilizou em torno desse tema, no dia 28 de abril foi divulgado o Parecer CNE/CP n ${ }^{\circ}$ 05/2020. Em sua análise de caminhos possíveis, é desconsiderada a realidade da grande maioria das crianças brasileiras, do amplo relatório gerado e declara um discurso amparado no uso das tecnologias de educação a distância, que agora aparece com outra roupagem de termos, substituindo o EAD por: "educação remota"; "atividades pedagógicas não presenciais" (BRASIL, 2020c).

Entre as possibilidades para a retomada das atividades escolares no período de pandemia, o Parecer 05/2020 aponta "a realização de atividades pedagógicas não presenciais (mediadas ou não por tecnologias digitais de informação e comunicação) enquanto persistirem restrições sanitárias para presença de estudantes nos ambientes escolares, garantindo ainda os demais dias letivos mínimos anuais/semestrais previstos no decurso" (BRASIL, 2020c, p. 06).

\footnotetext{
${ }^{3} \mathrm{http}: / /$ www.mieib.org.br/wp-content/uploads/2020/04/POSICIONAMENTO-MIEIB-PARA-O-CNE-FINAL19.04.2020.pdf
}

Olhar de professor, Ponta Grossa, v. 24, p. I-9, e-15877.019, 2021.

Disponível em <https://revistas2.uepg.br/index.php/olhardeprofessor> 
Dessa forma, a indicação de diversas entidades representativas participantes da chamada pública foi a da flexibilização do calendário e, para tanto, a resposta dada pelo Parecer 05/2020 foi a de que não é competência do CNE deliberar sobre esse assunto. Foi citada a autonomia prescrita na LDB em seu artigo $23, \S 2^{\circ}$, que o calendário escolar deverá adequar-se às peculiaridades locais, inclusive climáticas e econômicas, a critério do respectivo Sistema de Ensino, sem, com isso, reduzir o número de horas letivas previsto nesta Lei, deixando a encargo dos Sistemas de Ensino a definição das ações no contexto atual de excepcionalidade imposto pela pandemia.

Por conseguinte, o Conselho Estadual de Educação do Paraná deliberou a exceção da oferta para a Educação Infantil: "Art. 2. ${ }^{\circ}$ Fica autorizada às instituições de ensino credenciadas e com cursos e modalidades já autorizados e/ou reconhecidos de Educação Básica e Educação Superior, com exceção para a educação infantil, a oferta de atividades não presenciais" (PARANÁ, 2020, s/p.). O Parecer 05/2020, por outro lado, direciona e faz indicações de atividades a serem realizadas por orientações dos pais ou responsáveis e ainda divide as atividades para creche e pré-escola, sinalizando ações para tal, como estimulação substituindo a escola, "transformando os momentos cotidianos em espaços de interação e aprendizagem" (BRASIL, 2020c, p. 10).

Nesse sentido, o documento desconsidera $\circ$ fato de que muitas famílias podem estar enfrentando problemas de diversas ordens: psicológicos, financeiros, violência doméstica, perda de familiares, sofrimento com os sintomas da doença em caso de estarem com o vírus, estarem em isolamento ou internados, além da possibilidade de continuarem trabalhando e ainda, o fato de analfabetismo e analfabetismo funcional ainda persistirem no Brasil ${ }^{4}$, o que dificulta $\circ$ processo do ensino em casa. Em outras palavras, as condições objetivas de vida não são consideradas pelo Parecer do Conselho Nacional de Educação. Como afirmam Coutinho e Côco (2020, p. I-2):

A centralidade de iniciativas voltadas ao cumprimento de carga horária associada a conteúdos, com o uso de plataformas virtuais, redes sociais, correio eletrônico, recursos de videoaulas e outros, parece negar nossa situação de excepcionalidade, em que se mostram as condições de desigualdade em que vivemos, também no acesso aos recursos tecnológicos. Marca-se um entendimento da educação infantil (El) como um serviço que precisa ser ofertado, como se fosse possível transpor o modelo presencial para um modelo a distância. Essa compreensão, além de não adequada aos processos educativos, vem impactando as dinâmicas familiares e afetando sobremaneira o trabalho docente.

\footnotetext{
${ }^{4}$ De acordo com o Instituto Brasileiro de Geografia e Estatística (IBGE), em 2018 havia II,3 milhões de pessoas analfabetas com 15 ou mais anos de idade. Disponível em:

https://agenciabrasil.ebc.com.br/educacao/noticia/2019-09/analfabetismo-resiste-no-brasil-e-no-mundo-doseculo-21.
} 
Em relação aos professores, além da pressão sofrida e do estresse gerado por todo esse contexto, o Parecer 05/2020 trabalha com a falsa ideia de que os professores possuem domínio das estratégias para oferta de atividade pedagógica de EAD, aparelhos tecnológicos, acesso a uma boa internet e, ainda, que as atividades podem ser vivenciadas do mesmo modo, como se as crianças estivem presentes no contexto da escola.

Nessas condições, muitos municípios e instituições, valendo-se da autonomia, atrelam a realização de tais atividades ao cumprimento da carga horária letiva: "Art. $1 \mathrm{I}^{\circ}$ - As atividades escolares não presenciais, realizadas por meio da mediação tecnológica e/ou considerando a utilização de outros meios complementares, serão consideradas como efetivo trabalho escolar, valendo para o cômputo da carga horária mínima anual” (LONDRINA, 2020, s/p.), e “[...] validar os registros/portfólio da criança por meio das atividades propostas pelas videoaulas no retorno das aulas presenciais" (CURITIBA, 2020, p. 6).

Diante desses exemplos, questionamos: como realizar a avaliação das ações sem a garantia do acesso? Como validar os dias letivos a partir dos 4 anos de idade? Especialmente se considerarmos que a criança aprende por meio das interações e da brincadeira, conforme prescrito nas Diretrizes Curriculares Nacionais para a Educação Infantil (BRASIL, 2009). Sabemos que as crianças aprendem nos diferentes momentos da rotina, que se humanizam nas relações que estabelecem com os outros, aprendem a cuidar de si, dos seus pertences, a conviver com os pares, e que, portanto, o currículo da Educação Infantil se concretiza como:

Art. $3^{\circ} \mathrm{O}$ currículo da Educação Infantil é concebido como um conjunto de práticas que buscam articular as experiências e os saberes das crianças com os conhecimentos que fazem parte do patrimônio cultural, artístico, ambiental, científico e tecnológico, de modo a promover o desenvolvimento integral de crianças de 0 a 5 anos de idade (BRASIL, 2009, p. I).

Em outras palavras, é inconcebível que a orientação de uma única atividade valide um conjunto de práticas a ser vivenciado no contexto da Educação Infantil, mesmo porque essa educação, de modo intencional, deve acontecer, como o próprio documento oficial ressalta, em espaços não domésticos (BRASIL, 2009).

E ainda, apesar das exigências para que professores e professoras registrem, mesmo por meio das plataformas digitais, o acompanhamento e avaliação das crianças, sem tê-las de fato como convalidálas, a ação torna-se insustentável frente ao próprio Parecer 05/2020, ressaltando "o registro do desenvolvimento das crianças, sem o objetivo de promoção, mesmo para o acesso ao ensino fundamental” (BRASIL, 2020c, p. 10).

Diante desse cenário apresentado, nossa preocupação também se faz pela propagação das desigualdades sociais, da oferta aparente de educação, que na realidade contribui ainda mais para a 
precarização do ensino, uma vez que não considera as condições objetivas de vida familiar e dos encaminhamentos para o trabalho pedagógico.

\section{Considerações finais}

A travessia da pandemia se configura muito difícil para todos nas diferentes esferas da vida. No campo da educação, concordamos com Hanna Arendt:

A educação é o ponto em que decidimos se amamos o mundo o bastante para assumirmos a responsabilidade por ele [...] é, também, onde decidimos se amamos nossas crianças o bastante para não expulsá-las de nosso mundo e abandoná-las a seus próprios recursos, e tampouco arrancar de suas mãos a oportunidade de empreender alguma coisa nova e imprevista para nós, preparando-as em vez disso com antecedência para a tarefa de renovar um mundo comum (ARENDT, 20I I, p. 234).

Nessa direção, consideramos que os enfrentamentos são necessários, por meio da acolhida das crianças, das profissionais da educação, das famílias. No entanto, entendemos que um dos caminhos é também a resistência. $O$ que significa dizer: (a) não aceitar aulas na versão EAD para crianças pequenas; (b) não se submeter a grandes grupos para compras de materiais apostilados e/ou cursos; (c) não demandar das famílias ações as quais não tenham condições objetivas para realizar.

A escola, enquanto lugar físico, não podemos frequentar, no entanto, as crianças não deixaram de existir. E para elas, especialmente as da periferia, a escola não era simplesmente um espaço físico, mas um lugar seguro, de acesso ao conhecimento, à alimentação saudável, de vida em sociedade com o direito de ser criança. Para essas e para todas as outras crianças, a resistência se configura na garantia da alimentação, no cuidado e especialmente na preservação da vida.

Com relação às orientações contidas no Parecer 05/2020, ressaltamos que a preocupação deve residir não simplesmente na forma de "ensinar" as crianças pequenas e cumprir o calendário letivo, ao contrário, na garantia da alimentação, na manutenção do vínculo com a escola e com as professoras, na preservação da infância e dos direitos das crianças.

\section{Referências}

ARENDT, H. Entre o passado e o futuro. 7 ed. São Paulo: Perspectivas, 20 I I.

BRASIL. Ministério da Educação. Lei 9.394, de 20 de dezembro de 1996. Estabelece as diretrizes e bases da educação nacional, 1996. Diário Oficial da União, Brasília, DF, 23 dez. 1996. p. 27833-4I. 
BRASIL. Conselho Nacional de Educação. Câmara da Educação Básica. Resolução CNE/CEB n 05 , de 28 de maio de 2009. Fixa as Diretrizes Curriculares Nacionais para a Educação Infantil. Brasília, 2009.

BRASIL. Conselho Nacional de Educação. CNE/Parecer 05/2020 de 28 de março de 2020c. Reorganização do Calendário Escolar e da possibilidade de cômputo de atividades não presenciais para fins de cumprimento da carga horária mínima anual, em razão da Pandemia da COVID-19. Disponível em: <https://www.semesp.org.br/wp-content/uploads/2020/05/Parecer-CNE-CP_5_2020.pdf >. Acesso em: 26 mai. 2020.

BRASIL. Medida Provisória de I de Abril de 2020b. Institui ○ Programa Emergencial de Manutenção do Emprego e da Renda e dispõe sobre medidas trabalhistas complementares para enfrentamento do estado de calamidade pública reconhecido pelo Decreto Legislativo $n^{\circ} 6$, de 20 de março de 2020, e da emergência de saúde pública de importância internacional decorrente do coronavírus (covid-19), de que trata a Lei $\mathrm{n}^{\circ}$ 13.979, de 6 de fevereiro de 2020, e dá outras providências. Disponível em: <http://www.in.gov.br/en/web/dou/-/medida-provisoria-n-936-de-I-deabril-de-2020-2507I 1934>. Acesso em: 26 mai. 2020.

BRASIL. Ministério da Educação. Base Nacional Comum Curricular. Brasília: MEC/CNE, 2017.

BRASIL. Ministério da Educação. Nota de esclarecimento de 18 de março de 2020a. Disponível em: <http://consed.org.br/media/download/5e78b3 I90caee.pdf>. Acesso em: 26 mai. 2020.

CAMPANHA NACIONAL PELO DIREITO À EDUCAÇÃO. Compilado de contribuições: à Proposta de Parecer que trata da Reorganização dos Calendários Escolares e a realização de atividades pedagógicas não presenciais durante o período de Pandemia da COVID-19, Abr.2020, São Paulo - SP. Disponível em: <https://www.mieib.org.br/posicionamento-publico-do-movimento-interforuns-deeducacao-infantil-do-brasil-mieib-relativa-a-proposta-de-parecer-do-conselho-nacional-de-educacaocne-sobre-reorganizacao-dos-calendarios-escolar/> Acesso em: 26 mai. 2020.

COUTINHO, Angela Scalabrin, CÔCO, Valdete. Educação a distância na educação infantil, não! Educação e cuidado com as crianças, suas famílias e profissionais docentes, sim! Anped, 08 mai.2020. Disponível em: <http://www.anped.org.br/news/educacao-distancia-na-educacao-infantilnao-colaboracao-de-texto-por-angela-scalabrin-coutinho> Acesso em: 27 mai. 2020.

CURITIBA. Instrução normativa $\mathbf{n}^{\circ} \mathbf{0 2}$. Estabelece orientações para realização das atividades pedagógicas para a Educação Infantil (Pré-Escola), Ensino Fundamental, Educação de Jovens e Adultos (EJA) Fase I e Educação Especial das unidades educacionais da Rede Municipal de Ensino de Curitiba, em decorrência da pandemia causada pela COVID-19. Disponível em:

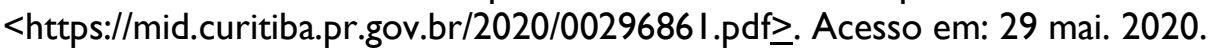

LONDRINA. Resolução $\mathbf{n}^{\circ} \mathbf{2 5}$ de $\mathbf{2 7}$ de maio de 2020. Orienta as unidades escolares da rede municipal de ensino de londrina sobre o desenvolvimento de atividades escolares não presenciais, em caráter de excepcionalidade, enquanto permanecerem as medidas de isolamento previstas pelas autoridades como prevenção e combate ao coronavírus e dá outras providências. Disponível em: $<$ http://repositorio.londrina.pr.gov.br/index.php/menu-educacao/educacao-e-a-covid-I 9/legislacao17/32254-resolucao-25-comissao-ped/file > Acesso em: 29 mai.2020.

PARANÁ. Conselho Estadual de Educação. Processo $n^{\circ}$ 32/2020 indicações n. ${ }^{\circ}$ 01/2020. Instituição de regime especial para o desenvolvimento das atividades escolares no âmbito do Sistema Estadual de Ensino do Paraná em decorrência da legislação específica sobre a pandemia causada pelo novo Coronavírus - COVID-19 e outras providências. Disponível em: 
<http://repositorio.londrina.pr.gov.br/index.php/menu-educacao/educacao-e-a-covid- | 9/3 | |40deliberacao-do-conselho-estadual-pr/file. > Acesso em 29 mai. 2020.

Recebido em: 10 de junho de 2020.

Versão corrigida recebida em: 24 de agosto de 2020.

Aceito em: 14 de setembro de 2020.

Publicado online em: 26 de março de 2021.

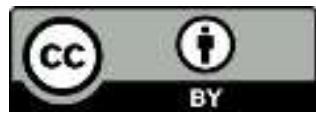

